\title{
Effect of blending and pregelatinizing order on properties of pregelatinized starch from rice and cassava
}

\author{
${ }^{1}$ Tô, H.T., ${ }^{2}$ Karrila, S.J., , ${ }^{3}$ gga, L.H. and ${ }^{1, *}$ Karrila, T.T. \\ ${ }^{I}$ Department of Food Science and Nutrition, Faculty of Science and Technology, Prince of Songkla \\ University, Pattani campus, Pattani 94000, Thailand \\ ${ }^{2}$ Faculty of Science and Industrial Technology, Prince of Songkla University, Surat Thani campus, \\ Surat Thani 84000, Thailand \\ ${ }^{3}$ School of Food Technology and Biotechnology, Hanoi University of Science and Technology, Ha Noi,
} Viet Nam

\begin{abstract}
Article history:
Received: 2 July 2019

Received in revised form: 9 August 2019

Accepted: 12 August 2019 Available Online: 20 August 2019
\end{abstract}

\section{Keywords:}

Non-additive effect,

Pasting properties,

Pregelatinized starch blends, Water absorption index

DOI:

https://doi.org/10.26656/fr.2017.4(1).245

\begin{abstract}
The aim of this work was to investigate the effects of processing order by mixing and pregelatinizing on properties of pregelatinized starch blends of cassava $(C)$ and rice $(R)$ starches, either mixed in various ratios $(0,10,30,50,70,90$ and $100 \% \mathrm{C})$ before pregelatinizing (MP) or with that order exchanged (PM, for pregelatinizing the components before mixing). Starch solids of $45 \%$ in water were pregelatinized using double drum drying at $120^{\circ} \mathrm{C}$. The water absorption index (WAI) and water solubility index (WSI) were measured, and pasting properties were characterized using Rapid Visco Analyzer (RVA). The results showed that MP (30 - 70\%C blends) had WSI half of that of $\mathrm{PM}$, while with $10 \% \mathrm{C}$ the former gave the higher WSI. In RVA viscosities, especially the hot peak viscosity, MP cases had significantly higher values $(p<0.05)$ than PM for all mixing ratios, indicating interactions in MP and less degradation of starch molecules. The choice of processing order gives some additional control over pregelatinized starch blend behavior in water, while a larger range of control is available by selection of the blend proportions.
\end{abstract}

\section{Introduction}

The native starches are unique in their properties and structure, and the various common native starches are quite versatile in terms of their functional properties. However, for industrial applications, the native starches require modifications that alter the properties (Santana and Meireles, 2014). There are several methods to modify starch, with preferences depending on the target product. Compared to chemical methods, physical methods are usually preferable for safe food products aimed at human consumption and require comparatively simple and easy processing (Ashogbon and Akintayo, 2014). Blending and pregelatinizing are common physical methods to manipulate the properties of starch for food products.

Binary blends of native starches have been studied for a few decades now (Waterschoot, Gomand, Delcour et al., 2015; Waterschoot, Gomand, Fierens et al., 2015). The two main factors that determine the blend properties are the types of starches, which relate to component starch properties, and their blending ratio. Each type of starch differs by, for example, starch granule size, amylose and amylopectin ratio, and the molecular structures. If a property of the blend is obtained from those of the components by weighing according to blend proportions (linear interpolation for blend between the pure components, similar to calculating the concentration of a chemical species), then the behavior is called "additive"; otherwise the behavior is "nonadditive" (Waterschoot, Gomand, Fierens et al., 2015). The practical meaning of non-additive behavior is that the blend properties cannot be predicted by the simplest linear interpolation between the components; instead, an operating curve must be experimentally determined, to connect mixture proportions with the outcome. In general, there is no reason to expect that a physical relationship would be linear, despite the apparent prior emphasis on explaining nonlinearity under the name "non-additivity". The mechanisms causing non-additive behavior of native starch blends have been attributed to granular interactions (Obanni and BeMiller, 1997); granule size differences (Puncha-arnon et al., 2008); swelling power differences (Waterschoot, Gomand, 
Delcour et al., 2015); and gelatinization temperature differences (Zhu and Corke, 2011). Those explanations relate to the behavior of starch when gelatinized. The observed effects have been in thermal, rheological, retrogradation and gelation properties

Pregelatinized starch is cooked and dried starch. It is also called alpha starch. It can be prepared by, for example, drum drying or spray drying. Pregelatinized starch is applied as a food thickening agent in infant foods and salad dressings (William, 2009) and in other non-thermally processed products. Successful creation of reduced-fat cream with a texture similar to full fat cream has been patented by Hirschey and Ragan (1992), based on pregelatinized instant starch mixed with sugar as the main component.

The important characteristic of pregelatinized starch is its ability to absorb water and solubilize, making a highly viscous slurry already below the gelatinization temperature, and in extreme cases even at ambient temperature. This behavior depends on the degree of starch conversion (or degradation) during gelatinization. The degradation of starch molecules is related to the starch type and processing conditions, especially temperature and starch content in the initial aqueous suspension. The key properties of pregelatinized starch with comparatively cool water are quantified by laboratory measurements of the water absorption index (WAI), the water solubility index (WSI), or the viscosity in cold water; or by determining the pasting properties at comparatively low temperatures.

Drum drying is a pre-cooking technique that is commonly used in the food industry to produce pregelatinized starch (Chung-wai and Daniel, 2009). Such dryer is mechanically simple and robust, allowing control of drum surface temperature and residence time on the drum before doctoring off the product. Cooking and drying a starch suspension on a hot drum gelatinizes the raw or native starch and modifies its key functional properties (BeMiller and Huber, 2015). The native starch is initially in a semi-crystalline state, but cooking in water degrades this structure and makes the starch, after drying, more soluble and more swellable, even in cool water. This is a significant advantage in various applications.

To our knowledge, there is no prior report on pregelatinized starch blends. While gelatinizing has been studied for starch blends, the current study goes a step further than those prior studies that did not form a dry powder and inspect its properties. On taking this further step, a novel question can be posed. If this kind of blend is prepared, should it be blended before or after pregelatinizing? The order of mixing and pregelatinizing processes may affect the properties of a pregelatinized starch blend: it is not completely characterized by the blend proportions.

Our research hypothesis, based on prior studies of starch blends, is as follows. When a mixture of native starches is pregelatinized they interact with some of the earlier proposed mechanisms; therefore the outcome (pregelatinized product) should not have the same properties as when pregelatinized component starches are mixed in the same proportions. So, the objective of the current study was to investigate the effects of order of mixing (M) and pregelatinizing (P), indicated here as (MP or PM), on the key properties of pregelatinized starch. Knowledge of such potential effects, and of their magnitude, can facilitate industrial process design when some combination of product properties is targeted.

\section{Materials and methods}

\subsection{Description and characteristics of raw materials}

Native rice and cassava starches were purchased from Thaiflour Industry Co., Ltd., Bangkok, Thailand. All the chemical reagents used were analytical grade. The native starch samples were characterized for some key properties: proximate chemical composition (moisture content, protein, lipid, fiber, and ash) following AOAC (2000); amylose content (Gibson et al., 1997); granule size distribution and average size ( $\mathrm{Li}$ and Yeh, 2001); crystalline pattern (Utrilla-Coello et al., 2014); swelling power and solubility at 60,75 and $90^{\circ} \mathrm{C}$ (Leach, 1959); pasting properties using Rapid Visco Analyzer (RVA), with "standard 1" profile (Tongdang, 2008); and gelatinization temperature and enthalpy (Sichina, 2000). The results are summarized in Table 1.

\subsection{Sample preparation}

The mixtures of raw rice (R) and cassava (C) starches, here called native starch blends (NB), had 10, $30,50,70$, or $90 \% \mathrm{C}(\% \mathrm{R}=100-\% \mathrm{C})$ by dry weight, and these were pregelatinized to obtain the MP cases. Also, the pure component starches were pregelatinized and then mixed in the same blend proportions (by dry weight) to obtain the PM cases.

\subsubsection{Mixing process for the NB samples}

Each NB mix batch was $1.5 \mathrm{~kg}$ by dry total weight. The amounts of cassava and rice starch were calculated from the blend ratio for $1.5 \mathrm{~kg}$ total dry weight, and from known dry weight and moisture content the necessary moist weight of each starch was determined. The proper amounts of component starches were blended in a $(40 \mathrm{~cm}$ $\mathrm{x} 40 \mathrm{~cm} \times 40 \mathrm{~cm}$ ) stainless box mixer (UP marketing, Bangkok Thailand) at $40 \mathrm{rounds} / \mathrm{min}$ for $2 \mathrm{hrs}$. The 
obtained NB samples were pregelatinized with a drum dryer to produce the MP cases, as described in 2.2.2

Table 1. Some properties of native rice and cassava starches

\begin{tabular}{lcc}
\hline \multicolumn{1}{c}{ Property } & Rice & Cassava \\
\hline Swelling power (g/g) at & & \\
$65^{\circ} \mathrm{C}$ & $3.00 \pm 0.24^{\mathrm{a}}$ & $3.33 \pm 0.16^{\mathrm{a}}$ \\
$75^{\circ} \mathrm{C}$ & $11.65 \pm 0.25^{\mathrm{b}}$ & $16.38 \pm 0.23^{\mathrm{a}}$ \\
$90^{\circ} \mathrm{C}$ & $14.65 \pm 0.42^{\mathrm{b}}$ & $25.38 \pm 0.28^{\mathrm{a}}$ \\
Solubility (\%) at & & \\
$65^{\circ} \mathrm{C}$ & $1.45 \pm 0.13^{\mathrm{a}}$ & $1.35 \pm 0.21^{\mathrm{a}}$ \\
$75^{\circ} \mathrm{C}$ & $4.81 \pm 0.52^{\mathrm{b}}$ & $7.25 \pm 0.36^{\mathrm{a}}$ \\
$90^{\circ} \mathrm{C}$ & $17.03 \pm 0.46^{\mathrm{b}}$ & $19.01 \pm 0.41^{\mathrm{a}}$ \\
RVA pasting & & \\
Pasting temp ( $\left.{ }^{\circ} \mathrm{C}\right)$ & $85.0 \pm 0.57^{\mathrm{a}}$ & $72.21 \pm 0.77^{\mathrm{b}}$ \\
Pasting time (min) & $5.62 \pm 0.21^{\mathrm{a}}$ & $4.24 \pm 0.04^{\mathrm{b}}$ \\
Peak viscosity (mPa.s) & $2095 \pm 38^{\mathrm{b}}$ & $3795 \pm 48^{\mathrm{a}}$ \\
Though viscosity (mPa.s) & $1486 \pm 40^{\mathrm{a}}$ & $1605 \pm 25^{\mathrm{a}}$ \\
Breakdown viscosity (mPa.s) & $610 \pm 37^{\mathrm{b}}$ & $2191 \pm 25^{\mathrm{a}}$ \\
Final viscosity (mPa.s) & $3271 \pm 104^{\mathrm{a}}$ & $2593 \pm 67^{\mathrm{b}}$ \\
Setback viscosity (mPa.s) & $1785 \pm 112^{\mathrm{a}}$ & $988 \pm 1^{\mathrm{b}}$ \\
Gelatinization (DSC) & & \\
$\mathrm{T}_{\text {onset }}\left({ }^{\circ} \mathrm{C}\right)$ & $68.67 \pm 0.52^{\mathrm{a}}$ & $65.40 \pm 0.36^{\mathrm{b}}$ \\
$\mathrm{T}_{\text {peak }}\left({ }^{\circ} \mathrm{C}\right)$ & $68.67 \pm 0.52^{\mathrm{a}}$ & $70.74 \pm 0.01^{\mathrm{a}}$ \\
$\mathrm{T}_{\text {conclusion }}\left({ }^{\circ} \mathrm{C}\right)$ & $83.52 \pm 0.28^{\mathrm{a}}$ & $81.19 \pm 0.11^{\mathrm{b}}$ \\
Enthalpy, $\Delta \mathrm{H}(\mathrm{J} / \mathrm{g})$ & $13.56 \pm 0.33^{\mathrm{b}}$ & $15.37 \pm 0.07^{\mathrm{a}}$ \\
\hline Aver & &
\end{tabular}

Average $\pm \mathrm{sd}$ of at least 3 replicates.

Values in the same row with different letters are significantly different $(\mathrm{p}<0.05)$.

\subsubsection{Pregelatinization process}

Aqueous NB starch slurries with $45 \%$ solids content of starch by dry weight were cooked and dried on a twindrum drier (Owner Foods Machinery Co. Ltd, Thailand) following Ilhan et al. (2003). Each drum had $16 \mathrm{~cm}$ diameter and $20 \mathrm{~cm}$ axial length, the gap was adjusted to $1 \mathrm{~mm}$, and the rotation speed was set at $1 \mathrm{rpm}$. The temperature of the drum surface was set at $120^{\circ} \mathrm{C}$, with heating provided by steam. The starch slurry was poured at the speed of $25 \mathrm{~g} / \mathrm{min}$, and the dried product doctored off the drums was ground to powder after tray drying at $55^{\circ} \mathrm{C}$ for about 40 mins, and then sieved through a 150 $\mu \mathrm{m}$ sieve. Moisture contents of all the pregelatinized products were in the $8-9 \%$ range.

Pregelatinized individual rice or cassava starches were prepared in a similar manner before mixing the PM cases, as described in 2.2.3

\subsubsection{Mixing process for PM samples}

On mixing the pregelatinized component starches, the total dry weight of each mixing batch was $200 \mathrm{~g}$. The moisture levels of the pregelatinized rice and cassava starches were determined, to enable correct amounts by dry weight. The batches were passed through 250 and $180 \mu \mathrm{m}$ sieves for 20 times by a horizontal circular motion sieve shaker (AS200 digit, Retsch GmbH, Germany), at 260 oscillations $/ \mathrm{min}$, to obtain homogenous mixtures.

\subsection{Microscopy}

The morphologies of native and pregelatinized samples were imaged with a scanning electron microscope $(1455 \mathrm{Vp}$, LEO, Cambridge, UK; $20 \mathrm{kV}$ accelerating voltage). Sample preparation was as described in Kaur et al. (2004).

\subsection{X-ray diffraction (XRD)}

Native starches, pregelatinized cassava and rice starches, and some PM or MP cases were tested for crystallinity using an X-ray diffractometer (X'Pert MPD, Philips, Netherlands) equipped with Ni-filtered $\mathrm{Cu} \mathrm{K}_{\alpha}$ radiation and operated at $40 \mathrm{kV}$ and $30 \mathrm{~mA}$, with $0.05^{\circ}$ steps and $3 \% \mathrm{~min}$ scanning speed. High Score Plus version 3.0e software (PANalytical, Netherlands) was used to extract the relative crystallinity $\left(\mathrm{X}_{\mathrm{c}}\right.$, in \%) from the observation range $4-35^{\circ}(2 \theta)$, and this used the following equation (Utrilla-Coello et al., 2014):

$$
\mathrm{X}_{\mathrm{c}}(\%)=\frac{\mathrm{A}_{\mathrm{c}}}{\mathrm{A}_{\mathrm{t}}}=\frac{\mathrm{A}_{\mathrm{c}}}{\mathrm{A}_{\mathrm{c}}+\mathrm{A}_{\mathrm{a}}} \times 100
$$

Where $A_{c}$ is the crystalline area; $A_{a}$ is the non-crystalline area; and $A_{t}$ is the total area.

\subsection{Water absorption index (WAI) and water solubility index (WSI)}

Exactly $0.45 \mathrm{~g}$ by dry weight of an MP or PM sample was loaded in a $15 \mathrm{~mL}$ centrifuge tube containing $1 \mathrm{~mL}$ of $99 \%$ pure ethanol. Water $(13.5 \mathrm{~mL})$ was then added to fill the tube and the screw cap was tightly closed. The sample was mixed well using mixing roller (MX-T6-S, Camlab, UK) at $50 \mathrm{rpm}$ for $3 \mathrm{hrs}$ at ambient temperature $\left(30^{\circ} \mathrm{C}\right)$. After that, the tube was centrifuged (HARRIER 15/80 benchtop refrigerated centrifuge, Sanyo, Japan) at $5870 \mathrm{RCF}$ (relative centrifuge force) for 10 minutes. The supernatant was carefully collected using a dropper, placed in an aluminum pan, dried at $105^{\circ} \mathrm{C}$ in a hot air oven, and then weighed $\left(\mathrm{m}_{\text {sol }}\right)$. The remaining wet sediment was also weighed $\left(\mathrm{m}_{\mathrm{sed}}\right)$. WAI and WSI were calculated as follows (Na Nakorn et al., 2009):

$$
\begin{aligned}
& \text { WAI }(\mathrm{g} / \mathrm{g})=\mathrm{m}_{\text {sed }} / 0.45 \\
& \text { WSI }(\%)=100 * \mathrm{~m}_{\text {sol }} / 0.45
\end{aligned}
$$

\subsection{RVA pasting properties}

The Rapid Visco Analyzer (RVA4D, Newport Scientific, Warriewood, Australia) with Thermocline for 
Windows software was used to determine the pasting properties of MP and PM cases of pregelatinized starch. The test profile was "extruding with alcohol" following RVA method 13.04 (Perten Instruments, 2017) with slight modifications in sample preparation. The analysis procedure for all samples was as follows. First, a $2.5 \mathrm{~g}$ sample by dry weight was placed in the RVA sample can containing $3 \mathrm{~mL}$ ethanol, to which $22 \mathrm{~mL}$ distilled water was added. The RVA paddle was used for a few seconds to homogenize the suspension, which was then checked to ensure the absence of clumps. The can and paddle were loaded into the device. The stirring speed was 960 rpm for the first 10 seconds and was thereafter maintained at $160 \mathrm{rpm}$ for the rest of a test run (20 mins in total). The initial $25^{\circ} \mathrm{C}$ temperature was held for 2 mins, ramped up to $90^{\circ} \mathrm{C}$ over 5 mins, held at $90^{\circ} \mathrm{C}$ for 3 mins, then ramped down to $25^{\circ} \mathrm{C}$ over 5 mins, and finally held at $25^{\circ} \mathrm{C}$ for the last 5 mins. The RVA characteristics extracted from each run were cold peak area, cold peak viscosity (maximum viscosity in the beginning at cold stage, $25^{\circ} \mathrm{C}$ ), hot peak (maximum viscosity in hot stage, $90^{\circ} \mathrm{C}$ ), hold (minimum viscosity at $90^{\circ} \mathrm{C}$ ), final, breakdown (difference between peak and hold viscosities) and setback (difference between final and hold) viscosities; and peak time (duration from beginning of the test to obtain hot peak viscosity).

\subsection{Data analysis}

The data reported in tables are averages of triplicate observations. Exploratory data visualizations were performed with the public domain software Data Warrior version 4.5.2 (Sander et al., 2015), which allows rapid graphical inspection of patterns in data. Select plots were later re-generated in Excel 2010 spreadsheets. The Duncan Multiple Rank Test (DMRT) for comparing means between treatments (significance requirement $\mathrm{p}<0.05$ ) was performed with SPSS version 17.0.

\section{Results and discussion}

3.1 Characteristics of native cassava and rice starch samples

The protein, lipid and ash contents for rice starch were $\quad 0.48 \pm 0.01, \quad 0.14 \pm 0.01, \quad 0.62 \pm 0.02 \% \quad(\mathrm{db})$, respectively while those for cassava were lower, 0.01 ., 0.02 and $0.18 \pm 0.03 \%(\mathrm{db})$, respectively. All these contents comply with Thai quality standards. Rice starch had higher amylose content than cassava starch $(23.13 \pm 0.33$ vs $18.18 \pm 0.11 \%$, db). The differences in chemical composition affect physicochemical properties of starches (Swinkels, 1985; Tester et al., 1990; Eliasson and Gudmundsson, 2006). For example during gelatinization, amylose and lipid could form complexes affecting the final viscosity (Kaur and Singh, 2000).
However, the RVA final viscosity (Table 1) for rice was higher than that for cassava, indicating that free leached amylose molecules in the paste influenced the final viscosity more than amylose-lipid complexation.

The average granule size of rice starch was much smaller than that of cassava starch $(7.89 \pm 5.71$ vs $13.06 \pm 5.73 \mu \mathrm{m})$, and this could influence for example swelling power and viscosity of starch. Table 1 shows some physicochemical properties. Swelling power, solubility as well as RVA viscosities are characteristics sensitive to changes in starch during heating in water (or gelatinization). Of the two starches, cassava showed higher RVA peak viscosity and swelling power at all tested temperatures. The ability of starch to absorb water is affected by its granule size and molecular arrangement in the granules. In this case, cassava had larger granules than rice, but the rice starch took longer to swell and reach peak viscosity, resulting in higher peak time and temperature than for cassava. This agrees well with the gelatinization temperatures obtained from DSC measurements. Therefore, it can be concluded that cassava starch was easier to degrade by heating with water than rice starch.

\subsection{Microscopy results}
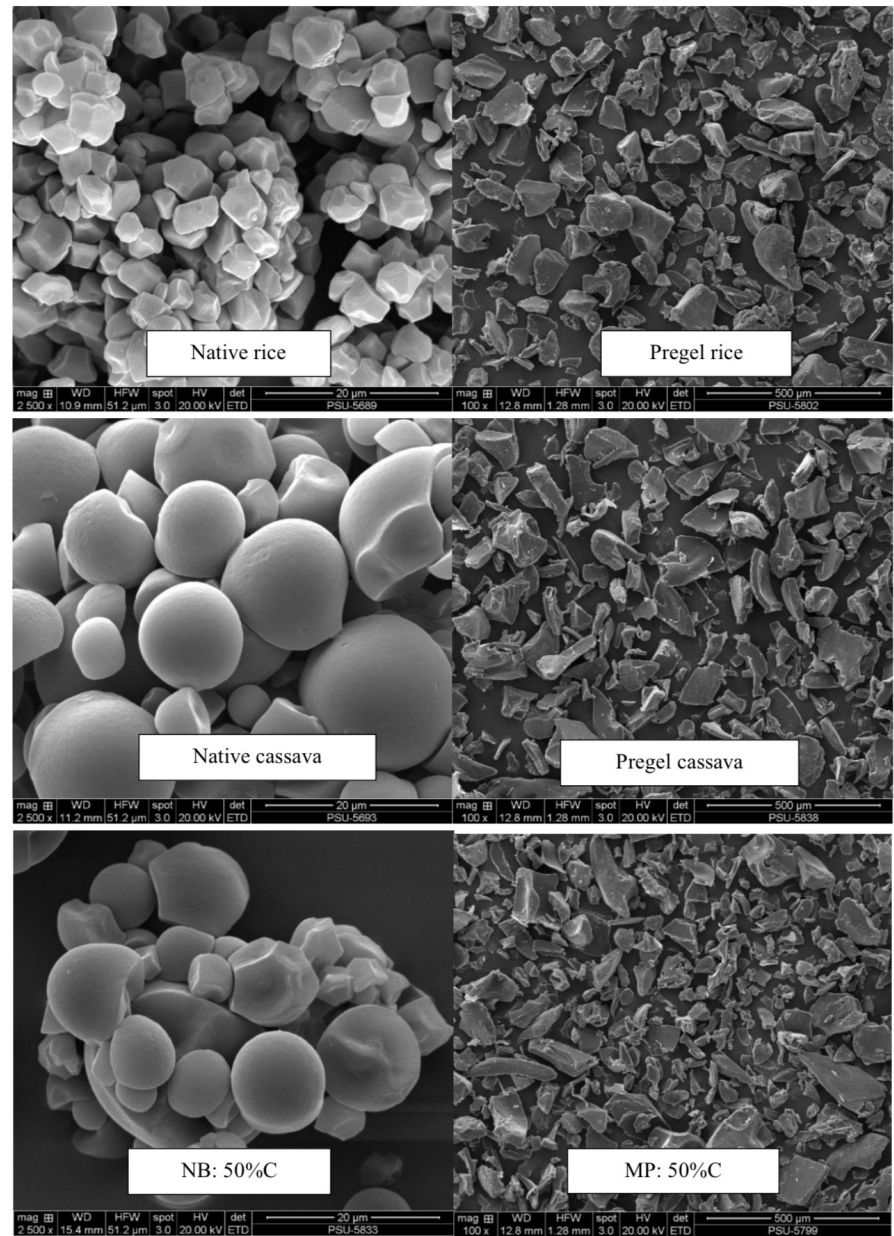

Figure 1. SEM micrographs of native cassava $(\mathrm{C})$, rice $(\mathrm{R})$ and their blend $(50 \% \mathrm{C})$ and of similar cases after pregelatinization (MP $50 \% \mathrm{C}$ ) 
SEM images of native cassava and rice, and their 1:1 blend, both before and after pregelatinizing, are shown in Figure 1. Native cassava granules are clearly different in shape and size from native rice starch. In the blend, rice starch granules seem to fill voids left between the larger cassava granules. No statistically significant effect of mixture proportions on bulk density of mixture was found. Only the 1: 1 ratio NB is shown, as a "fair" equal proportions mix of rice and cassava starches. No obvious differences between the pregelatinized samples were observable.

\section{$3.3 X R D$}

XRD diffractograms of native starches, pregelatinized rice and cassava starches, and the MP and PM cases with 50\% cassava are given in Figure 2. Both native rice and cassava starches show A-type crystalline pattern, in agreement with prior reports (Klein et al., 2013). Regarding the pregelatinized samples, the XRD patterns without sharp diffraction peaks distinguish these cases from the native starches, indicating that the semicrystalline structure was destroyed and converted to amorphous. However, small amounts of crystalline phase remained, in the range 3-5\%. Probably these samples pregelatinized by drum drying contained a variety of modification levels, as has been reported previously (BeMiller and Huber, 2015). Material close to the hot drum gains heat while exposed to water, but the open surface exposed to air is quickly dehydrated and loses heat rapidly - the processing by drum drying is not uniform and gives a heterogeneous product.

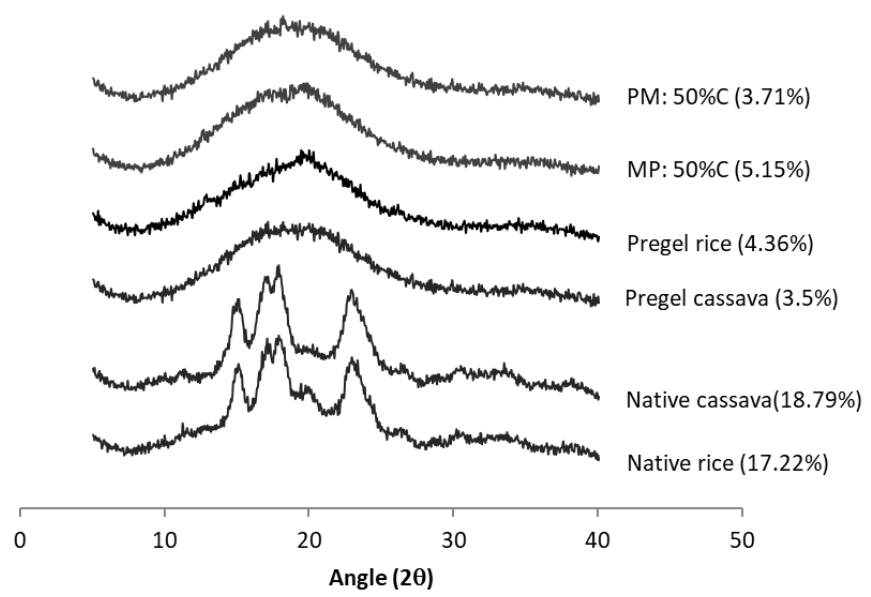

Figure 2. X-ray diffractograms of native cassava and rice starches, pregelatinized cassava and rice starches, and $50 \% \mathrm{C}$ pregelatinized starch blends. Percentages shown in the legend are crystallinities. MP had mixing before pregelatinizing, while PM cases are mixtures of separately pregelatinized rice and cassava.

\subsection{Water absorption index (WAI) and water solubility index (WSI)}

WAI and WSI (Figures 3a and 3b) were consistently lower for pregelatinized rice than for pregelatinized cassava. Rice had higher gelatinization temperature as well as pasting temperature, hence during pregelatinization its molecules were degraded less than those of cassava, giving lower WAI and WSI. This suggests that the granule structure or rice was stronger and more resistant than the structure of cassava granules, otherwise, the smaller rice granules would be easier to penetrate and convert than the larger cassava granules.

(a)

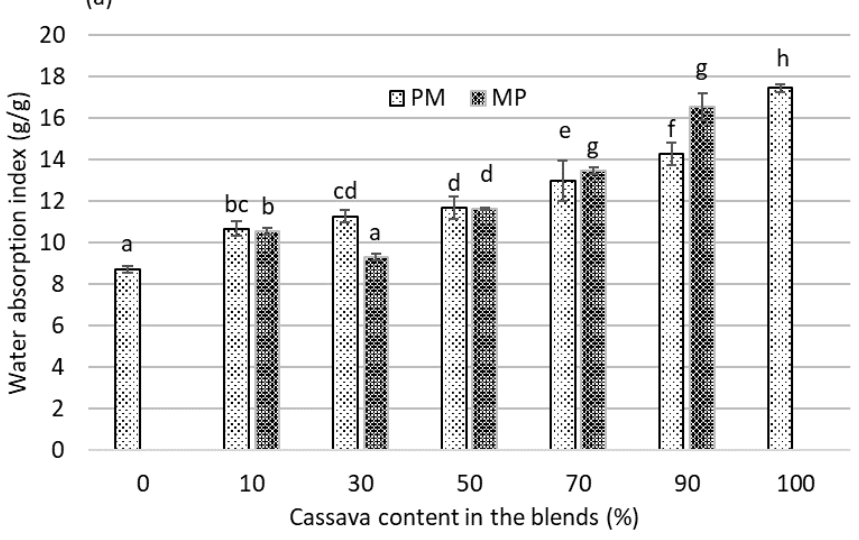

(b)

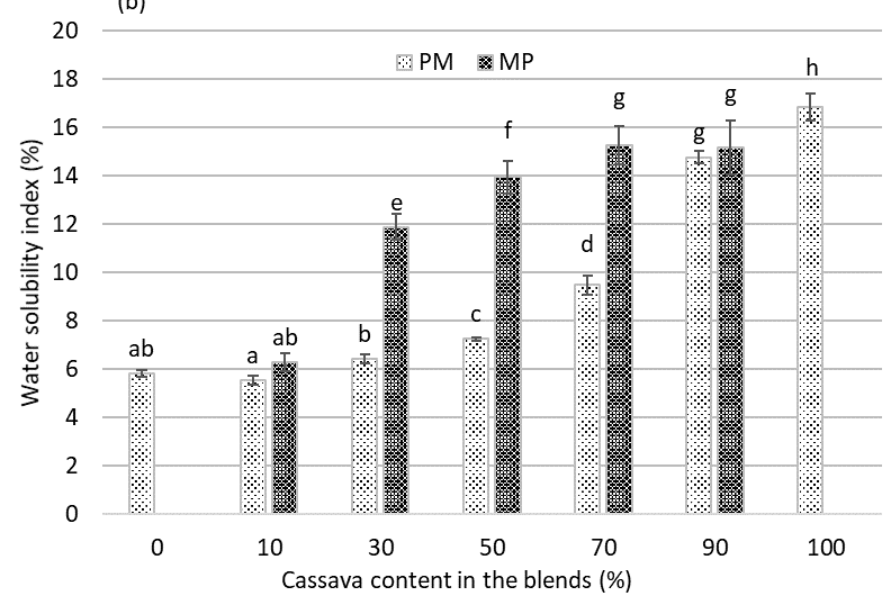

Figure 3. Comparison of water absorption index (a), and water solubility index (b) between MP and PM samples across various cassava contents in the blend. MP indicates mixing before pregelatinizing, and PM indicates mixture of separately pregelatinized native cassava and rice. Different letters above bars indicate significant differences $(\mathrm{p}<0.05)$.

Regarding WAI in Figure 3a, the MP and PM cases did not differ except in the cases with $30 \% \mathrm{C}$ and $90 \% \mathrm{C}$. When rice dominated over cassava in the blend ratio, WAI was greater for MP than for PM, and the order was reversed when cassava content was dominant. While the overall pattern can be considered inconsistent, this indicates that the order of processing steps can affect starch conversion. The hypothetical mechanisms that could induce the observed behavior are now discussed.

In the $90 \% \mathrm{C}$ mixture of native starches, the small amount of small-sized rice granules could fill gaps between the larger cassava granules (Waterschoot, Gomand, Fierens et al., 2015) which increases bulk density and limits access to water in MP processing. This 
reduced starch degradation during heating and hence gave comparatively low WAI, while in PM processing the different native granule sizes had no impact.

For the $30 \% \mathrm{C}$ mixtures, MP processing gave clearly lower WAI than PM, but without any such difference at the neighboring mixing ratios $50 \% \mathrm{C}$ and $10 \% \mathrm{C}$. This could be explained by molecular entanglement between the component starches, which would be maximal at some specific proportions (Doublier et al., 1984). The observed WAI responses to blend proportions do not overall match linear interpolation, so this property had non-additive behavior in the current study.

The WSI (Figure 3b) behaved in an expected manner, in that the "almost pure" mixes $(90 \% \mathrm{C}$ and $10 \%$ C) showed no effect from the order of processing. This is because the pure extremes with only one component starch have no difference between MP and PM, and by the continuity of physical macroscopic properties the nearby cases should not show much difference either. However, the balanced mix with $50 \% \mathrm{C}$ and its neighboring cases showed large WSI differences between MP and PM. Thus both blend ratio and processing order had large effects on solubility of the product, with MP processing maximally reducing solubility to about half of that with PM.

Solubility is attributed to the leaching of small/short molecules that can be dissolved in water, while the large (high degree of polymerization) molecules would sediment during centrifugation (Mitchell et al., 1997).

The degradation of starch molecules during gelatinization contributes to the solubility of pregelatinized starch, which depends on its degree of degradation ( $\mathrm{Na}$ Nakorn et al., 2009). The higher solubility with PM than with MP might be explained as follows.

First, the heterogeneous mixture of cassava and rice starches, in the MP case, may resist gelatinization and deterioration, reducing solubility. Second, the leached molecules from one starch may recombine or react with the other during hydration (Doublier et al., 1984; Puchaarnon et al., 2008; Waterschoot, Gomand, Delcour et al., 2015) forming complexes of amylose and amylopectin that decrease solubility - also this is only relevant to MP processing.

The WSI, WAI, and degree of starch degradation are interconnected for a specific starch (Na Nakorn et al., 2009). However, Figures $3 a$ and $3 b$ demonstrate that choosing between MP and PM processing gives added opportunities for control of these properties, i.e. to break such correlation. It may be concluded that manipulating starch component ratio and the order of processing can produce a wide variety of property combinations for pregelatinized starch, in effect creating new and different products. Such new products, of course, could be the components creating further new mixtures - at least in the case of MP processed components. Instead, mixing PM type products should give just another PM type product, bringing nothing new to the product palette.

The differences also mean that linear interpolation cannot apply with both types of processing; actually both MP and PM show non-additivity in WAI and WSI. Therefore, experimental operating curves for each need to be established to control properties of the final product, and Figure 4 shows these for blends of cassava and rice starch in this study, regarding the RVA characteristics.

\subsection{Pasting properties}
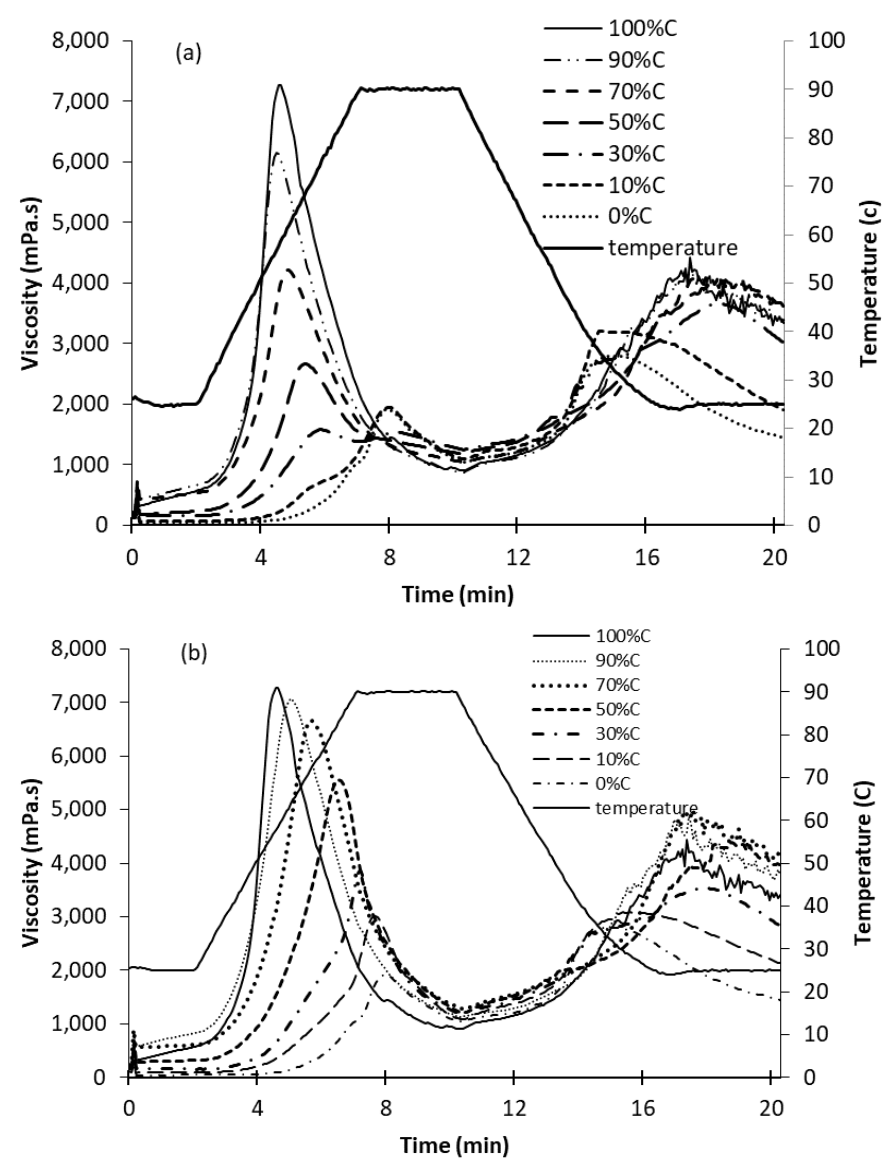

Figure 4. RVA viscograms of (a) MP, and (b) PM samples, with various cassava (C) contents in the blends. MP had mixing before pregelatinizing, while PM cases are mixtures of pregelatinized rice and cassava.

RVA viscograms for the MP and PM cases are shown in Figure 4, and the pasting characteristics extracted from the viscograms are plotted in Figures 5 and 6.

Of the pregelatinized pure components, cassava had a higher raw peak, breakdown, and setback viscosities; but lower hold viscosity than rice. Peak viscosity was the 
(a) Cold peak

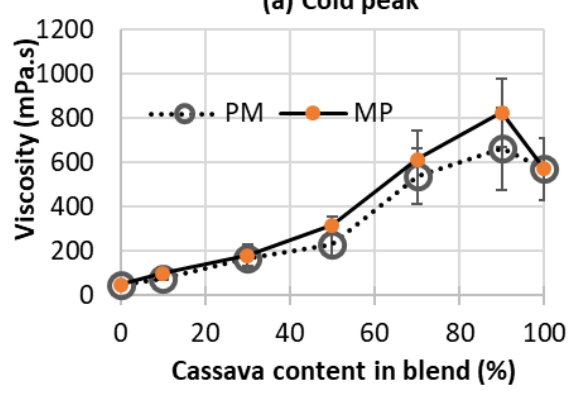

(c) Hot peak

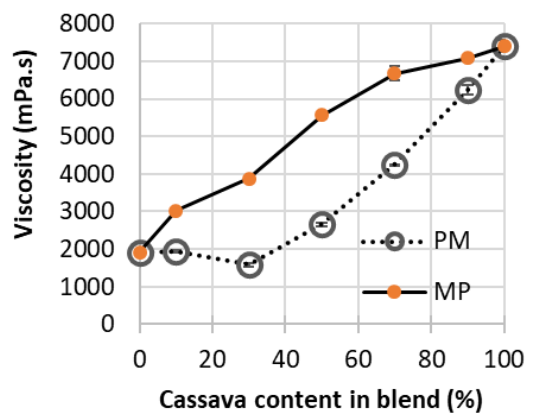

(b) Cold peak area

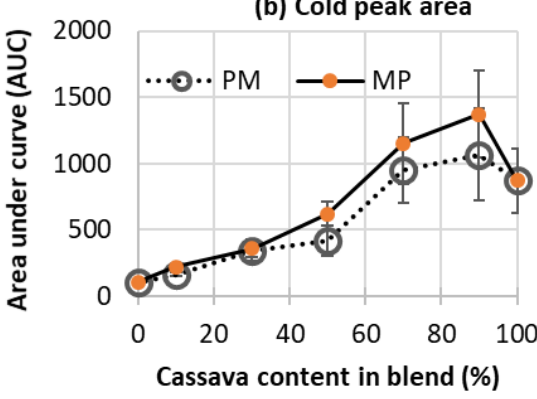

(d) Peak time

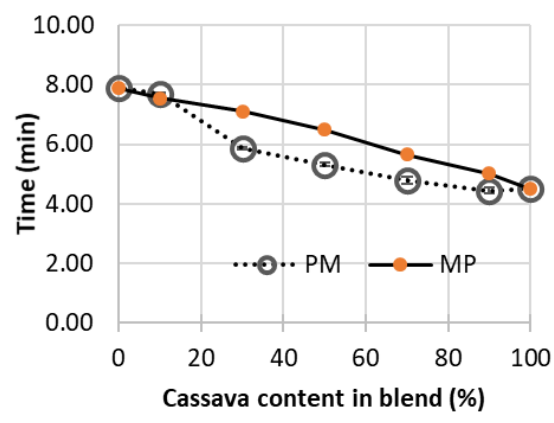

Figure 5. Comparison of RVA parameters between MP and PM cases with various cassava contents in the blend; (a) cold peak viscosity; (b) cold peak area; (c) peak viscosity; and (d) peak time

(a) Hold

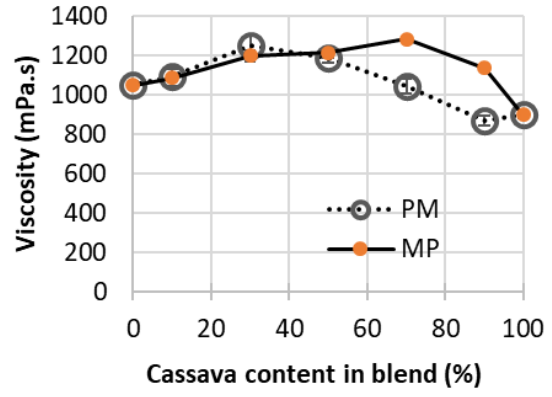

(c) Breakdown

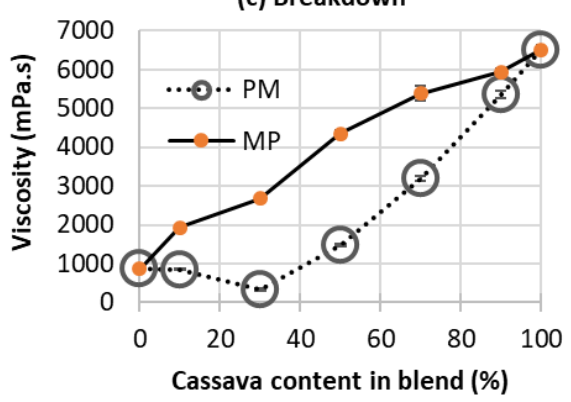

(b) Final

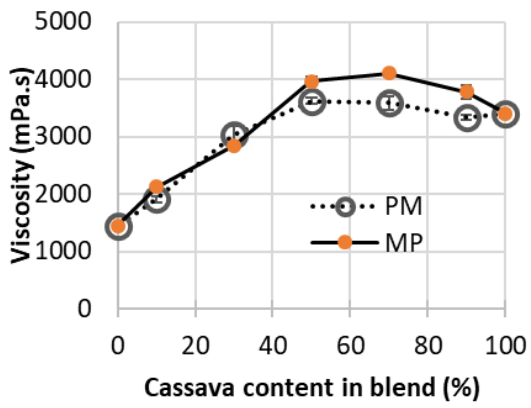

(d) Setback

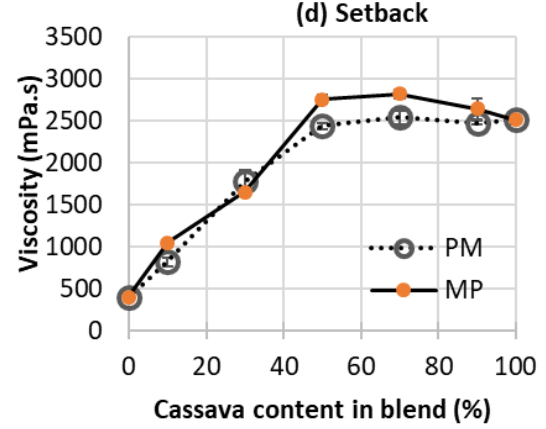

Figure 6. Comparison of RVA parameters between MP and PM cases with various cassava contents in the blend; (a) hold viscosity; (b) final viscosity; (c) breakdown viscosity; and (d) setback viscosity. MP had mixing before pregelatinizing, while $\mathrm{PM}$ cases are mixtures of pregelatinized rice and cassava.

maximum viscosity of sample during heating, which indicates the ability of the sample to absorb water. Clearly, the viscosities read from viscograms were in general higher for the MP than for the PM cases. Atwell et al. (1988) stated that pasting involves swelling of the granules, leaching of carbohydrates, formation of a three -dimensional network of leached molecules, and interactions between granules or granule remnants. MP allowed interactions between the different starches (granules, swollen granules and granule fragments) during gelatinization, and these are typically stronger than within a single starch (Obanni et al., 1997; Waterschoot et al., 2016), while PM had blending after pregelatinization, so no interactions in wet state between the different starches were possible.

In Figures 5a, and 5b, cold peak viscosity matches the cold peak area. These RVA parameters indicate the ability of pregelatinized starch to generate viscosity in cool water $\left(25^{\circ} \mathrm{C}\right)$. They should correlate positively with 
the WAI.

In particular, the hot peak viscosity (Figure 5c) showed large effects $(p<0.05)$ from the order of processing steps at any fixed blend proportions. Nonadditive blending effects (not following a straight line) were overall common. Effectively hot peak and breakdown (Figure 6c) viscosities are tied together since the viscosity after breakdown is almost constant across all the cases: in Figures $5 \mathrm{c}$ and $6 \mathrm{c}$ the graphs are almost identical.

The peak time for pregelatinized rice was higher than that for cassava. For the blends, it decreased with cassava proportion, as seen in Figure 5d. The peak time with MP processing was greater than or equal to that with PM. The time needed to achieve maximum (or hot peak) viscosity, i.e. the peak time, was additively affected by the blend ratio with MP but not with PM processing, and tended to decrease with cassava content. The maximum difference in peak times between MP and $\mathrm{PM}$ cases was found at $30 \% \mathrm{C}$. This corroborates interactions between the different starches in MP processing during gelatinization.

RVA hold viscosity is the minimum viscosity after hot peak viscosity, at a constant temperature with shear. If the molecules cannot resist shear but get degraded, the viscosity will decrease more than with molecules that can resist shear. In Figure 6a the hold viscosity is higher for pregelatinized rice than for pregelatinized cassava and by continuity, the whole range between these pure components is covered by the blends. However, the blends display such synergy that they also get values outside this range. This might be due to molecular entanglements between the two-component starches and occurs with both MP and PM processing. The effect of processing order on hold viscosity is clear with $\geq 50 \% \mathrm{C}$, with the maximal difference at around 70 to $90 \% \mathrm{C}$. It appears that a dominant cassava fraction supports those interactions in MP processing that distinguish this from PM processing by the early pasting responses.

The graphs in Figures $6 \mathrm{~b}$ and $6 \mathrm{~d}$ show the final and setback viscosities. They are similar for MP and PM cases. These viscosities increased with cassava proportion in the blend for both cases. However, this behavior is different from native starch. For a native starch, the final and setback viscosities indicate retrogradation due to amylose network formation when the starch paste is cooled. As shown in Table 1, rice starch had higher final viscosity than cassava, as expected from its higher amylose content. On blending these two native starches, the final viscosity increased with rice starch fraction in the blend (data not shown). The behavior of pregelatinized blends (both MP and PM) is exactly the opposite, now the final viscosity follows cassava content. In fact, pregelatinization dramatically reduced the final RVA viscosity of rice starch, while in contrast it somewhat increased the final viscosity of cassava starch, thereby making cassava content the dominant contributor to final viscosity.

\subsection{Observations from exploratory analysis of results}

The collected data were explored from a multitude of plots, and only select observations of interest are presented here (Figures $7 \mathrm{a}$ and $7 \mathrm{~b}$ ).
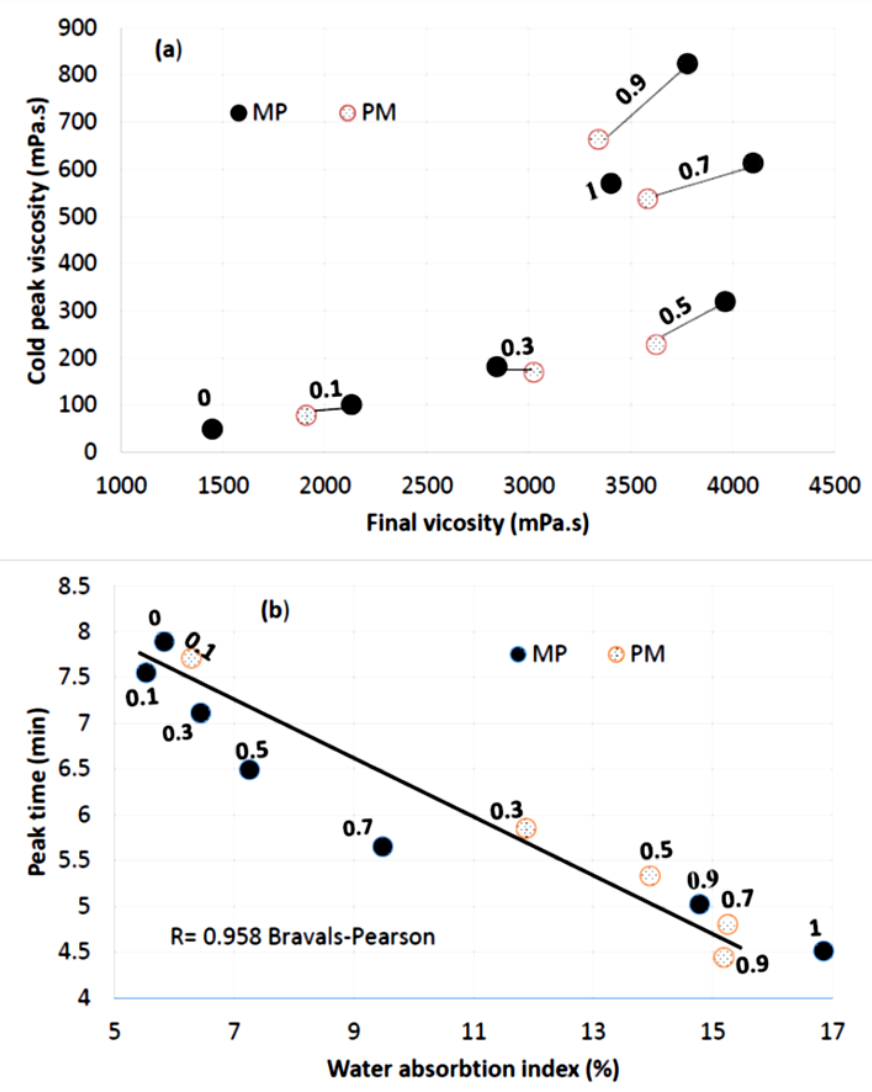

Figure 7. Relationships of selected properties of MP and PM processed starch blends. (a) Cold peak viscosity vs. final viscosity, and (b) peak time vs. WSI, across the tested cassava -rice blend proportions. Bold numbers in the graph indicate cassava fraction in the blends. MP had mixing before pregelatinizing, while PM cases are mixtures of pregelatinized rice and cassava.

The cold peak is the change of viscosity in the first 2 minutes of the RVA profile when water is still cold. Recrystallized amylose is not soluble in cold water, instead only the remnants of hydrated granules with amylopectin and the small molecules from scission during pregelatinization can absorb water and change the viscosity in cold water. Thus, the factors determining the cold peak are different from those determining the final viscosity, so these two characteristics do not correlate well.

In Figure 7a, when the cassava fraction is dominant the final viscosity remains nearly constant, but the cold 
peak viscosity can be adjusted by mixture proportions. Choice of the order MP or PM allows small adjustments to the final viscosity in this range of blend ratios. When the rice fraction is dominant the final viscosity can still be controlled over its whole range, and the cold peak viscosity follows it linearly but stays comparatively small, below about half that of pregelatinized pure cassava. Relative to the blend ratio, the choice of MP or PM processing order has only a smallish effect size. The overall strongly nonlinear character of Figure 6a confirms the non-additivity of pasting properties. The difference between MP and PM increased with cassava content, although pure cassava cannot possibly show any difference. In particular, a 10\% fraction of rice starch can increase the cold peak viscosity of pregelatinized cassava starch by about $40 \%$ with MP, but only by less than $20 \%$ with PM processing. This might relate to the packing density of starch granules when they are mixed before pregelatinization and their competition for water. Since the cold peak of pregelatinized rice starch is comparatively low, this large effect from a small addition of rice to cassava is opposite to what linear interpolation would anticipate: the observed effect is counter-intuitive in both magnitude and direction.

Figure $7 \mathrm{~b}$ shows the high Pearson correlation (0.96) between peak time and water solubility index, indicating that both these measurements are reasonably accurate physical descriptors without much corrupting measurement noise. For native granular starch, the peak time relates to granule and molecular strengths, showing how long the granules resist heating before completed initial dissolution and dispersion. For the pregelatinized starches of this study, the peak time relates to the degree of conversion, as high conversion should give rapid dissolution and short peak time. The WSI, in turn, relates to small molecules that can resist sedimentation during centrifuging, and has earlier been reported as an indicator of granular integrity or starch conversion, and as correlated to RVA viscosity (Morris, 1990; Sriburi et al., 1999; Na Nakorn et al., 2009). The MP and PM cases separately follow the rank order of blend proportions, but with large shifts between these two processing alternatives. This further confirms nonadditivity or interactions, and that both peak time and WSI are well-behaved physically meaningful determinations.

\section{Conclusion}

Both the blend ratio and the order of mixing and pregelatinizing steps had large effects on the properties of pregelatinized starch. The results clearly showed that MP and PM processing orders differ, which corroborates that during pregelatinization the molecular interactions of different starches are stronger than those for a single starch. The choice of processing order gives some additional control over pregelatinized starch blend behavior in water, while a larger range of control is available by selection of the blend proportions. In combination, these control variables allow the tailoring of pregelatinized starch for desired properties or improved control over quality variations. Overall, the results show that blending starches, before or after pregelatinization, is a powerful low-cost means to create pregelatinized starches targeting a desired combination of the key properties: viscosity, WAI, and WSI

\section{Conflict of interest}

The authors declare no conflict of interest.

\section{Acknowledgements}

This work was supported by the Faculty of Science and Technology, Prince of Songkla University, Pattani Campus, Thailand, (project code: SAT600912S) and by the graduate school of Prince of Songkla University.

\section{References}

AOAC. (2000). Official methods of analysis of AOAC International. Arlington, VA.: AOAC.

Ashogbon, A.O. and Akintayo, E.T. (2014). Recent trend in the physical and chemical modification of starches from different botanical sources: A review. StarchStärke, 66(1-2), 41-57. https://doi.org/10.1002/ star.201300106

Atwell, W.A., Hood, L.F., Lineback, D.R., VarrianoMarston, E. and Zobel, H.F. (1988). The terminology and methodology associated with basic starch phenomena. Cereal Foods World, 33, 306-311.

BeMiller, J.N. and Huber, K.C. (2015). Physical modification of food starch functionalities. Annual Review of Food Science and Technology, 6, 19-69. https://doi.org/10.1146/annurev-food-022814015552

Chung-wai, C. and Daniel, S. (2009). Modification of Starches. In BeMiller, J.N. and Huber, K.C. (Eds). Starch: Chemistry and Technology, p. 629-648. Amsterdam: Elsevier.

Doublier, J., Colonna, P. and Mercier, C. (1984). Extrusion cooking and drum drying of wheat starch. I. Physical and macromolecular modification. Cereal Chemistry, 61, 583-588.

Eliasson, A.C. and Gudmundsson, M. (2006). Starch: Physiochemical and Functional Aspects. In Eliasson A.C. (Ed). Carbohydrates in Foods, p. 391-470. New York: CRC Press. https:// 
doi.org/10.1201/9781420015058.ch10

Gibson, T., Solah, V. and McCleary, B. (1997). A procedure to measure amylose in cereal starches and flours with concanavalin A. Journal of Cereal Science, 25(2), 111-119. https://doi.org/10.1006/ jcrs. 1996.0086

Hirschey, J.A. and Ragan, L.F. (1992). Aerated reducedfat cream and process of making. In Google Patents No. US0051514942A.

Ilhan, E., Findik, F. and Aslanlar, S. (2003). An investigation of the factors affecting the design of drum dryers. Materials and Design, 24(7), 503-507. https://doi.org/10.1016/S0261-3069(03)00108-0

Kaur, K. and Singh, N. (2000). Amylose-lipid complex formation during cooking of rice flour. Food Chemistry, 71(4), 511-517. https://doi.org/10.1016/ S0308-8146(00)00202-8

Kaur, M., Singh, N., Sandhu, K.S. and Guraya, H.S. (2004). Physicochemical, morphological, thermal and rheological properties of starches separated from kernels of some Indian mango cultivars (Mangifera indica L.). Food Chemistry, 85(1), 131-140. https:// doi.org/10.1016/j.foodchem.2003.06.013

Klein, B., Pinto, V.Z., Vanier, N.L., da Rosa Zavareze, E., Colussi, R., do Evangelho, J.A., Gutkoski, L.C. and Dias, A.R.G. (2013). Effect of single and dual heat-moisture treatments on properties of rice, cassava, and pinhao starches. Carbohydrate Polymers, 98(2), 1578-1584. https://doi.org/10.1016/ j.carbpol.2013.07.036

Leach, H.W. (1959). Structure of starch granules. I. Swelling and solubility patterns of various starches. Cereal Chemistry, 36, 534-544.

Li, J.-Y., and Yeh, A.-I. (2001). Relationships between thermal, rheological characteristics and swelling power for various starches. Journal of Food Engineering, 50(3), 141-148. https:// doi.org/10.1016/S0260-8774(00)00236-3

Mitchell, J.R., Hill, E.S., Paterson, L., Valles, B., Barclay, F. and Blanshard J.M.V. (1997). The Role of Molecular Weight in the Conversion of Starch. In Frazier, P., Donald, M.A. and Richmond P. (Eds). Starch Structure and Functionality, p 68-76. Cambridge: The Royal Society of Chemistry.

Morris, V. (1990). Starch gelation and retrogradation. Trends in Food Science \& Technology, 1, 2-6. https://doi.org/10.1016/0924-2244(90)90002-G

Na Nakorn, K.N., Tongdang, T. and Sirivongpaisal, P. (2009). Crystallinity and rheological properties of pregelatinized rice starches differing in amylose content. Starch-Stärke, 61(2), 101-108. https:// doi.org/10.1002/star.200800008
Obanni, M. and BeMiller, J.N. (1997). Properties of some starch blends. Cereal Chemistry, 74(4), 431436. https://doi.org/10.1094/CCHEM.1997.74.4.431

Perten Instruments. (2017). Perten Instruments Method Description RVA method 13.04. Retrieved on January 8, 2017 from Website: www.perten.com/.../ RVA/Extrusion\%20method\%20-\%20RVA\% 2013.04.pdf.

Puncha-arnon, S., Pathipanawat, W., Puttanlek, C., Rungsardthong, V. and Uttapap, D. (2008). Effects of relative granule size and gelatinization temperature on paste and gel properties of starch blends. Food Research International, 41(5), 552561. https://doi.org/10.1016/j.foodres.2008.03.012

Sander, T., Freyss, J., von Korff, M. and Rufener, C. (2015). DataWarrior: an open-source program for chemistry aware data visualization and analysis. Journal of Chemical Information and Modeling, 55 (2), 460-473. https://doi.org/10.1021/ci500588j

Santana, Á.L. and Meireles, M.A.A. (2014). New starches are the trend for industry applications: a review. Food and Public Health, 4(5), 229-241. https://doi.org/10.5923/j.fph.20140405.04

Sichina, W. (2000). Use of DSC for the Characterization of Starches. PerkinElmer Instruments.

Sriburi, P., Hill, S.E. and Mitchell, J.R. (1999). Effects of L-ascorbic acid on the conversion of cassava starch. Food Hydrocolloids, 13(2), 177-183. https:// doi.org/10.1016/S0268-005X(98)00080-0

Swinkels, J.J.M. (1985). Composition and properties of commercial native starches. Starch-Stärke, 37(1), 15. https://doi.org/10.1002/star.19850370102

Tester, R.F. and Morrison, W.R. (1990). Swelling and gelatinization of cereal starches. I. Effects of amylopectin, amylose, and lipids. Cereal Chemistry, 67(6), 551-557.

Tongdang, T. (2008). Some properties of starch extracted from three Thai aromatic fruit seeds. Starch-Stärke, 60(3-4), 199-207. https://doi.org/10.1002/ star.200800641

Utrilla-Coello, R., Hernández-Jaimes, C., CarrilloNavas, H., González, F., Rodríguez, E., Bello-Perez, L. A., Vernon-Carter, E. and Alvarez-Ramirez, J. (2014). Acid hydrolysis of native corn starch: morphology, crystallinity, rheological and thermal properties. Carbohydrate Polymers, 103, 596-602. https://doi.org/10.1016/j.carbpol.2014.01.046

Waterschoot, J., Gomand, S.V. and Delcour, J.A. (2016). Impact of swelling power and granule size on pasting of blends of potato, waxy rice and maize starches. Food Hydrocolloids, 52, 69-77. https:// doi.org/10.1016/j.foodhyd.2015.06.012 
Waterschoot, J., Gomand, S.V., Delcour, J.A. and Goderis, B. (2015). Direct evidence for the nonadditive gelatinization in binary starch blends: A case study on potato starch mixed with rice or maize starches. Food Hydrocolloids, 50, 137-144. https:// doi.org/10.1016/j.foodhyd.2015.04.020

Waterschoot, J., Gomand, S.V., Fierens, E. and Delcour, J.A. (2015). Starch blends and their physicochemical properties. Starch-Stärke, 67(1-2), 1-13. https:// doi.org/10.1002/star.201300214

William, R.M. (2009). Starch use in Food. In BeMiller, J.N. and Huber, K.C. (Eds). Starch: Starch Chemistry and Technology, p. 746-772. Amsterdam, Elsevier

Zhu, F. and Corke, H. (2011). Gelatinization, pasting, and gelling properties of sweet potato and wheat starch blends. Cereal Chemistry, 88(3), 302-309. https://doi.org/10.1094/CCHEM-10-10-0145 